\title{
Movimientos etnopolíticos contemporáneos y sus raíces organizacionales en el Sistema de Interdependencia Regional del Orinoco
}

Contemporary ethnopolitical movements and their organizational origins in the Orinoco Regional Interdependency System

\section{Nelly Arvelo-Jiménez}

\section{(2) OpenEdition Journals}

\section{Edición electrónica}

URL: http://journals.openedition.org/aa/1276

DOI: $10.4000 /$ aa. 1276

ISSN: 2357-738X

Editor

Programa de Pós-Graduação em Antropologia Social (UnB)

Edición impresa

Fecha de publicación: 1 diciembre 2014

Paginación: 133-160

ISSN: 0102-4302

\section{Referencia electrónica}

Nelly Arvelo-Jiménez, «Movimientos etnopolíticos contemporáneos y sus raíces organizacionales en el Sistema de Interdependencia Regional del Orinoco», Anuário Antropológico [En línea], v.39 n.2 | 2014 Publicado el 01 agosto 2017, consultado el 28 abril 2021. URL: http://journals.openedition.org/aa/ 1276 ; DOI: https://doi.org/10.4000/aa.1276

\section{(9) $\odot \Theta \Theta$}

Anuário Antropológico is licensed under a Creative Commons Atribuição-Uso Não-Comercial-Proibição de realização de Obras Derivadas 4.0 International. 


\section{Movimientos etnopolíticos contemporáneos y sus raíces organizacionales en el Sistema de Interdependencia Regional del Orinoco}

Nelly Arvelo-Jiménez

IVIC

\section{Introducción}

Analizamos las implicaciones de las huellas que hemos detectado en los movimientos etnopolíticos indígenas contemporáneos en el Sistema de Interdependencia Regional Horizontal del Orinoco (SIRO). Este último ya fue objeto de investigación y análisis en artículos anteriores (Arvelo-Jiménez, 1979; Arvelo-Jiménezet al., 1990; Arvelo-Jiménez \& Biord Castillo, 1994; Biord Castillo, 1985). El SIRO cobra realidad como síntesis que deviene de la relectura de trabajos etnográficos propios realizados en sociedades del tronco lingüístico Caribe, ubicadas geo-culturalmente en la cuenca del Orinoco, junto a reinterpretaciones de las crónicas europeas de los siglos XVI y XVII, de reinterpretaciones de las narrativas de naturalistas europeos que exploraron el Orinoco y sus afluentes en el siglo XIX, de los resultados etnográficos aportados por otros antropólogos, etnohistoriadores, lingüistas y arqueólogos especializados en las culturas pertenecientes a la matriz civilizatoria orinoco-amazonense, y está vinculada con textos de la historia oral de la sociedad Yekuana o Dekuana. Dado el carácter de reconstrucción histórica con un porcentaje bajo de testimonios directos, siempre asumimos el SIRO como un modelo heurístico que, por derivarse de un abordaje histórico y estructural, ha hecho posible la identificación de vinculaciones significativas entre los movimientos etnopolíticos contemporáneos con los movimientos de resistencia militar dirigidos por los jefes militares kariña durante los siglos XVI, XVII y parte del XVIII (Morales Méndez, 1979), así como con muchos otros ocurridos a lo largo de los siglos subsiguientes. Esta relectura de la sinergia de procesos de dominación/resistencia, cambio cultural y apropiación de recursos culturales ajenos, fragmentación y reconstitución étnicas, a lo largo de las etapas proto-colonial, colonial y neo-colonial, se afianza en nuestro empeño por construir un diálogo entre el antiguo acontecer político colonial y las circunstancias políticas de la Venezuela contemporánea. Uno de los temas que debe ser dilucidado gravita en torno a la relación sociocultural y política entre indígenas y criollos. Hemos hilvanado la trayectoria de las etnias 
de la matriz orinoco-amazonense desde el momento del impacto de la conquista europea y la respuesta indígena de creación y recreación de transfiguraciones étnicas que nos permiten discernir el contrapunteo dialéctico entre fragmentación y reconstitución étnicas. Pensamos que la relación entre cambio, fortalecimiento, sobrevivencia cultural y persistencia del fenómeno étnico, lejos de ser contradictoria y degenerativa, es transformadora y nos permite, hoy día, trazar las raíces organizacionales de los movimientos indígenas contemporáneos en el Sistema de Interdependencia Regional del Orinoco.

En referencia a los movimientos etnopolíticos contemporáneos introdujimos una división analítica arbitraria entre el acontecer político colonial y post-colonial, y la movilización política contemporánea. Esta división no la percibimos como una ruptura en el hilo conductor de la historia indígena sino como una diferencia metodológica. Los enfrentamientos militares que ofrecieron indígenas como los Kariña en los primeros siglos de la conquista europea, la simulación de sumisión que invisibiliza la reacción indígena a la dominación europea expresada a través de la aparente aceptación de la vida en reducciones católicas, y las fugas planificadas aunque no anunciadas hacia regiones de refugio son testimonios indirectos provenientes del lente colonizador de europeos y criollos. En tanto que para los movimientos contemporáneos los analistas del proceso sociopolítico de cambio, apropiación y resistencia somos antropólogos, historiadores y politólogos criollos, testigos y observadores participantes de dicho proceso, para cuya interpretación cabal añadimos entrevistas y grabaciones de exégesis proporcionadas por los dirigentes indígenas y la incorporación de las críticas que esos dirigentes formulan de nuestras interpretaciones. Hemos llevado un registro minucioso de los movimientos contemporáneos en cuyo desenvolvimiento los indígenas dejan aflorar mecanismos por ellos congelados en el tiempo, revitalizándolos y combinándolos con apropiaciones de tecnologías modernas y tácticas políticas externas a su patrimonio cultural. Tal es el caso de la utilización del inmenso poder que tienen los medios de comunicación masiva: radio, prensa y televisión. Hemos presenciado cómo los indígenas amplían su repertorio de resistencia con formas de protesta criollas, por ejemplo las "tomas u ocupaciones" pacíficas de las sedes regionales de oficinas indigenistas gubernamentales, las marchas contestatarias frente a las sedes de los distintos poderes públicos, desde el Congreso Nacional, pasando por el Palacio de Miraflores o Casa presidencial, las sedes regionales de los Ministerios en las capitales de los estados o en Caracas, capital de la República. Igualmente, no han descartado acciones que involucran cierta violencia física como el bloqueo de carreteras y el derrumbe y destrucción de infraestructuras instaladas de manera inconsulta 
en tierras ancestrales. Este es el caso de los indios Pemón, quienes recurrieron a mecanismos institucionales, pacíficos y muy costosos a lo largo de más de veinte años, en sus múltiples intentos para reivindicar el reconocimiento oficial de la propiedad de sus tierras ancestrales. Sus dirigentes hicieron ingentes sacrificios económicos para viajar hasta Caracas y entrevistarse con diputados, senadores y ministros, con gobernadores y algunos presidentes sin obtener una solución jurídica inequívoca sobre la propiedad de sus tierras. Hasta que en los años noventa del siglo XX fueron arrastrados por una avalancha de decisiones gubernamentales inconsultas que aún los afectan y perjudican ambiental y económicamente, como en los casos de la Reserva Forestal de Imataca y de la construcción del tendido eléctrico para surtir de energía al norte del Brasil, el cual se analiza en detalle más adelante. La mencionada Reserva, situada al nordeste de la Gran Sabana, que era un área de conservación o área bajo régimen de administración especial (ABRAE) fue desafectada mediante el decreto ejecutivo No. 1850 de 1997 para permitir la explotación de oro y madera. En el curso de las protestas en contra de la rezonificación de la Reserva Forestal de Imataca, los Pemón establecieron una alianza con ambientalistas e indigenistas criollos. Esta alianza les proporcionó una visibilidad de primer plano en el escenario nacional y le dio una proyección cibernética a la lucha pemón en contra de la minería a gran escala y de la construcción e instalación de las líneas de alta tensión que forman parte del tendido eléctrico que surte de energía a los estados brasileños de Roraima y Amazonas.

El segmento temporal que escogimos para estudiar los movimientos etnopolíticos abarca los últimos 30 años, vale decir, el lapso durante el cual hemos podido observarlos en pleno curso de acción a través de un detallado seguimiento de sus diferentes fases y tácticas. Igualmente, contrastamos la evaluación realizada por analistas políticos externos a la realidad indigenista venezolana con nuestra propia evaluación sobre la visibilidad e impacto de esos movimientos etnopolíticos en la opinión pública y en los acontecimientos políticos del país. Calibramos estas dos últimas variables en función de la resonancia que percibimos, tanto en círculos gubernamentales como en las respuestas de intelectuales, articulistas y políticos criollos publicadas y difundidas en los medios de comunicación.

El catalizador de la movilización indígena contemporánea fue la invasión de tierras indígenas en la Región Sur de Venezuela también denominada, entre 1969-1974, Área Marginal/Fronteriza. Estas invasiones fueron la respuesta de los criollos a la propuesta gubernamental llamada "Conquista del Sur", la cual fue planteada al país en términos de políticas de Estado concernientes al desarrollo y al ejercicio de la soberanía nacional en dicha área, que coincide, a 
grandes rasgos, con la extensión de la parte sur de la cuenca del Orinoco. Algunos de los territorios ancestrales indígenas recibieron casi de inmediato el impacto de proyectos especulativos (Arvelo-Jiménez, 1971) que llevaron adelante los citados invasores impulsados por la posibilidad imaginada de acumular lucro fácil a través de la apropiación y expropiación de tierras tradicional y ancestralmente indígenas pero jurídicamente baldías (Valdez, 1971). Para entender las características estructurales y funcionales de los movimientos etnopolíticos que irrumpieron en el escenario político nacional y en los medios de comunicación masiva, y que fueron inicialmente protagonizados por los indígenas Yekuana, utilicé mis conocimientos etnológicos sobre los pueblos indígenas habitantes de la cuenca del Orinoco, recurriendo al análisis diacrónico de la matriz cultural orinoco-amazonense como marco de referencia cultural.

\section{El Sistema de Interdependencia Regional del Orinoco (SIRO)}

Los cronistas y pensadores europeos de los siglos XVI al XVIII inventaron un limbo histórico para referirse a los modos de vida de los pueblos indígenas que encontraron a su paso los conquistadores de América, asumiendo que de esta manera racionalizaron su presencia en suelo americano. Limbo histórico o inexistencia de la historia antes de la invasión europea, con la cual creyeron justificar la dominación, la conquista, la expropiación de riquezas indígenas y la esclavitud de los pueblos y gentíos que los europeos fueron contactando. Esta tesis del limbo histórico permaneció sin ser refutada ni por los indios americanos ni por la intelectualidad criolla independentista en el siglo XIX y, peor aún, ha sido inadvertidamente reforzada por dos camadas de antropólogos contemporáneos.

La intelectualidad criolla, que pertenecía a la clase mantuana privilegiada y dominante, cuando estuvo delante de la ocasión de delinear los elementos fundadores del futuro Estado nacional venezolano, se auto-eximió de toda responsabilidad o complicidad en la explotación de los indígenas, cuando simultáneamente con el acto de declaración de su independencia de España fingió haber sido víctima del español peninsular, en aparente paridad de condiciones con los segmentos realmente oprimidos de indios, negros y pardos. Perpetuó con esta ficción histórica, a través de los siglos y en las subsiguientes generaciones, la construcción oficial que se enseña como historia patria, según la cual la guerra de independencia sirvió para cristalizar una ruptura total con España y con el pasado. La guerra de independencia, como proyecto propio de la clase mantuana o criolla les permitió aparentar la transmutación de clase dominante en víctimas del yugo español. 
Los antropólogos profesionales durante el siglo XX no han cesado de reiterar, mediante la interpretación de sus resultados científicos, la tesis colonial del limbo histórico y de la máxima desarticulación política supuestamente inherente a las sociedades y culturas indígenas. Los primeros en sustentarlo fueron antropólogos procedentes de Estados metropolitanos, como por ejemplo en la síntesis por áreas geo-culturales que aportó Julian Stewart (1948) en el Handbook of South American Indians, en el cual se caracteriza a las formaciones sociales orinoquenses, parte de la amplia matriz civilizatoria del bosque tropical húmedo, mediante representaciones falaces repletas de metáforas e imágenes evocadoras de desarticulación política y carencias culturales. Estas supuestas carencias no sólo encajan armónicamente con la perspectiva colonial europea sino que a la vez refuerzan la negación del indio y de las culturas orinoquenses. También arqueólogos, etnohistoriadores y etnólogos criollos han inyectado mayor fuerza a esa tesis debido a que interpretan sus resultados según líneas teóricas copiadas de la antropología metropolitana. Esta dependencia con la metrópolis perpetúa la percepción colonial que describe a las sociedades en cuestión como "bandas" políticamente desarticuladas que sobreviven en medio de un permanente estado de guerra. Estos investigadores locales se suman inadvertidamente a las filas de los productores de saberes y conocimientos coloniales, creando la condición descrita por Aníbal Quijano como “colonialidad del saber” (Quijano, 2000). Sus resultados científicos reafirman la existencia de colectividades exentas de mecanismos e instituciones de integración incapaces, por definición externa, de crear formas de articulación de mayor amplitud y cobertura que la del grupo local y, consecuentemente, que sólo se conectan de manera accidental con otros pueblos de la cuenca del Orinoco a través del trueque ocasional de bienes y productos, o de constantes fricciones bélicas.

En mi primer análisis etnográfico de los Yekuana o Dekuanas, Political Relations in a Tribal Society: a Study of the Ye'cuana Indians of Venezuela (Arvelo-Jiménez, 1971), logré a través del análisis de genealogías, migraciones e historias orales realizar un corte sincrónico de doscientos años en el devenir de este pueblo, asumiendo tácitamente que ese lapso temporal fue suficiente para aprehender, describir y transmitir la dinámica de su sistema político. Por ende, en esta etnografía también se perpetúa la metáfora de la desarticulación en la medida que esta sociedad es descrita como si fuera una isla auto-contenida, con independencia total del resto de las sociedades indígenas con las cuales compartió y comparte no sólo el espacio geográfico de la cuenca del Orinoco sino una matriz civilizatoria común. Quedaron sin explorar posibles conexiones significativas dentro del marco regional mayor y el estudio temporal profundo de las raíces 
histórico-culturales de esta sociedad, que tiene una antigüedad milenaria, dentro del devenir de los pueblos que construyeron el horizonte civilizatorio del bosque tropical húmedo con sus particularidades orinoquenses.

Este abordaje interpretativo, muy vigente en los años setenta y parte de los ochenta, sólo parece estar resquebrajándose durante publicaciones recientes, puesto que frente al cúmulo de datos y al énfasis dado a las historias orales de los pueblos indígenas a etnólogos y etnohistoriadores les es imposible referirse peyorativamente a evidencias fragmentarias y disímiles que se redondean y construyen alrededor de especulaciones. Aunque persisten las fidelidades a fórmulas y mediciones con tecnología importada de la física o la matemática, de flujos de energía, etc., el resto de los antropólogos parece comenzar a admitir que la acumulación de datos enriquecidos por las memorias colectivas de estos pueblos exige un marco interpretativo que explique el sentido del dinámico acontecer histórico en el cual surgieron, funcionaron, batallaron, se desarrollaron y robustecieron las formaciones sociales orinoquenses a lo largo de milenios de historia.

En 1979 el aporte pionero de Morales Méndez descubrió un infinito mundo de perspectivas interpretativas. El empeño de Morales Méndez en profundizar en el estudio de la continuidad cultural del pueblo Kariña lo distingue entre la mayoría de los analistas que, cuando estudian los cambios socioculturales producto de la conquista y la colonización europeas, la neo-colonización criolla y de las consecuencias del vigente sistema postcolonial venezolano, acentúan la involución cultural y profetizan la desaparición definitiva de las etnias orinoquenses (por ejemplo, Perera 1992 y Cruxent, 1948, citados en Scaramelli y Tarble, 2000). El ejemplo de la trayectoria de los Kariña y de su papel en el juego de fuerzas políticas con eje en el propio Orinoco me enseñó a escuchar y pulsar el ritmo de los cambios de estas sociedades a través de los siglos y a rastrear sus conexiones vitales con otros pueblos indígenas de la cuenca. Revisé con una perspectiva totalmente fresca mis resultados y los de otros investigadores, descubriendo en ellos nuevas claves para ampliar mi propio abordaje antropológico. Los datos ya acumulados por etnohistoriadores, cronistas y etnógrafos en sus intentos por aprehender la historia cultural de los pueblos indígenas del Orinoco fueron releídos y me condujeron a un abordaje holístico para lograr una comprensión integral que iluminó con otra luz mi conclusión de que las sociedades indígenas de esta cuenca no pueden entenderse aisladamente sino en conjunto, y que intentar descripciones de la cultura kariña o de la cultura yekuana como si ambas fueran y siempre hubieran sido islas culturales sólo refuerzan los errores de comprensión del "otro" que han rodeado a los pueblos amerindios desde que los europeos reemplazaron la historia oral, que era la historiografía 
autóctona, por su historiografía. Coetáneamente con los resultados de Morales Méndez, Urbina Flores (1979), al estudiar un sistema económico, aporta datos sobre la organización sociopolítica de los Pemón actuales que, juntándolos y comparándolos con las interpretaciones ya mencionadas de Morales Méndez para los Kariña y las mías propias sobre los Yekuana (Arvelo-Jiménez, 1971, 1974), constituyen el corpus inicial de los elementos estructuradores del modelo interpretativo que acuñé en 1979 como Sistema de Interdependencia Regional Horizontal del Orinoco (SIRO).

Al utilizar el calificativo de horizontal para el Sistema de Interdependencia Regional Orinoquense quiero recalcar el contraste entre dos posibles sistemas de integración política. Es decir, entre la integración horizontal que privilegia la autonomía local ejercida soberanamente por las formaciones sociales conectadas por el SIRO y el sistema de integración vertical de pisos ecológicos con implicaciones de subordinación política descrito lúcidamente por Murra en 1975 y reanalizado por Bigenho (1996). La horizontalidad orinoquense exhibe otra propiedad importante que es su condición de centralizarse temporalmente sin desembocar en la formación de Estados o de otros sistemas políticos de estructura vertical que llevan inherentemente la sujeción política de las colectividades que los constituyen. Por el contrario, la horizontalidad orinoquense funciona entre autonomías locales y regionales para las cuales la centralización es posible cuando amenazas de guerra o severas crisis políticas coloquen en riesgo la integridad de todos los componentes del sistema (Morales Méndez, 1979; Arvelo-Jiménez \& Morales Méndez, 1981; Biord Castillo, 1985; Arvelo-Jiménez et al., 1990; Arvelo-Jiménez \& Biord Castillo, 1994; Whitehead, 1990, 1994; Arvelo-Jiménez, 2000).

Hemos hecho referencia también al hecho de que estas formaciones sociales orinoquenses utilizan los principios de parentesco y las prestaciones y contraprestaciones que emanan de una sociedad regida por principios de parentesco, donde la reciprocidad ordena el intercambio de mujeres, de bienes y servicios, la conformación de los grupos mayores de la familia nuclear poseedora de imbricadas relaciones sociales, políticas, económicas y religiosas, o relaciones multiplex (Gluckman, 1965). Esto quiere decir que la lógica que las gobierna no secciona o separa las relaciones en campos de acción y reflexión especializados, tal como acontece con nuestras relaciones económicas, políticas, religiosas, ecológicas, etc. Las relaciones en sociedades de reciprocidad son multiplex y generalizadas. Las sociedades orinoquenses, al organizarse según el parentesco y la reciprocidad, tienen que establecer relaciones multiplex en sus interacciones sociales intra e interétnicas. Sugerí, y sostengo, que las relaciones entabladas en las ferias 
de verano (Coppens, 1972; Thomas, 1972; Butt, 1973; Morey, 1975; Morey \& Morey, 1975) y/o a través de negociadores interétnicos que recorrían las rutas o caminos interfluviales fueron relaciones de naturaleza múltiplex y de circulación generalizada. Mi lectura es la de que los intercambios caracterizados por etnógrafos y etnohistoriadores como solamente "comerciales" deben haber estado acompañados por intercambios sociales, acuerdos políticos, prestación de servicios religiosos y económicos, introducción, difusión y adopción de modas, circulación de noticias e informaciones estratégicas, etc. Todos estos intercambios promovidos y realizados por miembros de sociedades horizontalmente conectadas que los practicaban regularmente sin temor a perder la independencia política de sus asentamientos, como sí hubiera sido en el caso de ocurrir dentro de la formación política de Estados o de cacicazgos dotados de ejércitos permanentes para conquistar, extender y defender fronteras étnicas territoriales. La intangibilidad e invisibilidad de algunas de estas relaciones multiplex han dificultado su percepción por analistas externos a esa realidad, quienes parecen asumir que sólo existe como hecho científico interpretable lo materialmente tangible. Luce igualmente probable que estos analistas nunca hayan trabajado con una cultura amazónica viva y no dan crédito a la existencia de concepciones metafísicas, y aún menos a la influencia de éstas, en la dinámica social orinoco-amazonense. Donde yo percibo un sistema de interrelaciones multiplex, cuyas manifestaciones materiales tangibles sólo afloran ocasionalmente pues el resto del tiempo permanecen latentes y relativamente invisibles, cobrando materialidad o visibilidad en las ferias comerciales y mediante centralizaciones político-militares motivadas por crisis políticas, otros estudiosos de las culturas orinoquenses sólo admiten la existencia de relaciones comerciales (Zucchi \& Gasson, 1986; Vidal, 1987; Heinen, 1992; Mansutti Rodríguez, 1992).

No obstante, recientes trabajos etnológicos (Smith, 1995; Pérez, 2000a, 2000b; y comunicaciones personales de Fernando Santos-Granero 2000 y Dominique Buchillet 2001), que abordan las formaciones sociales indígenas orinoco-amazonenses o afroamericanas con influencia orinoquenses, tienden a corroborar la pervivencia de algunas de las características que describí y conceptualicé como elementos del Sistema de Interdependencia Regional del Orinoco.

En Amazonia: economía indígena y economía de mercado, Smith (1995) interpreta los resultados de una investigación realizada por cinco equipos diferentes de investigadores que focalizaron sus actividades en la identificación de variables claves que deben formar parte de programas de diversificación económica y de articulación de las economías indígenas amazónicas contemporáneas con la economía de mercado de Brasil, Perú, Colombia, Ecuador y Bolivia. La investigación 
alcanzó su objetivo a través del análisis de las causas de éxito o fracaso de microempresas económicas introducidas en forma experimental durante la década de los ochenta del siglo XX. Surgieron algunas variables comunes a todos los casos estudiados, las cuales parecen explicar el por qué del fracaso económico de todas las que fueron sometidas a evaluación. Algunas de las causas responsables por el fracaso las introdujeron las financiadoras de ayuda internacional y remiten a premisas erróneas sobre el funcionamiento de las organizaciones sociales indígenas amazónicas, mientras otras están íntimamente relacionadas con la naturaleza de las sociedades receptoras de la ayuda técnica y económica. Smith interpreta los resultados arrojados por la investigación usando como marco la racionalidad de las economías indígenas, lo cual le permite caracterizar las actividades económicas indígenas como elementos de un sistema regido por el parentesco y la reciprocidad, del cual deriva la conclusión de que la racionalidad económica indígena está en contradicción básica con la racionalidad económica capitalista. Además sentencia que hasta que los miembros de las actuales sociedades indígenas amazónicas no se liberen de las obligaciones, prestaciones y contraprestaciones que regulan los principios de parentesco, jamás podrán entablar entre ellos relaciones simples de naturaleza económica ni, por ende, relaciones capitalistas exitosas. Estos resultados refuerzan una de las premisas del SIRO, la del ejercicio de relaciones sociales multiplex. Después de cinco siglos de cambios, los actores sociales pertenecientes a varios pueblos indígenas de la Amazonia no consiguen seccionar y aislar sus relaciones sociales ni imaginarlas de manera diferente de las relaciones multiplex que les son familiares. Si llegaran a seccionarlas y simplificarlas, incurrirían en flagrantes violaciones de las normas sociales, lo cual seguramente les llevaría a la violencia social y política que deviene de la transgresión de otras obligaciones y relaciones sociales. Durante los doscientos, trescientos o cuatrocientos años transcurridos desde que sufrieron los procesos de conquista y colonización, las respectivas sociedades dominantes no han logrado erradicar ni suplantar los principios que rigen la interacción social entre las sociedades indígenas de la Amazonia.

Ha sido hasta ahora difícil acumular datos historiográficos sobre las huellas del SIRO y/o las transformaciones experimentadas dentro del Sistema durante el siglo XIX. Existen, no obstante, datos esporádicos sobre los intercambios indígenas que ocurrían en los pueblos criollos, fundados por los españoles en el siglo anterior, entre indios asentados o reducidos e indios interfluviales que habían conservado su autonomía. Existen dos factores que permiten hipotetizar que desde 1830 y hasta la llegada del frente extractivo cauchero los indígenas de las áreas interfluviales fueron abandonados temporalmente del celo 
neo-colonizador de los criollos, permitiendo a los indígenas continuar manejando sus interconexiones con los pueblos de la cuenca del Orinoco. Esto se debió, por una parte, a que el Estado nacional venezolano estuvo enredado en múltiples guerras que ocurrieron todas al Norte del Orinoco y, por otra, según los fragmentos de historia oral de pueblos orinoquenses con los que he trabajado, a que los mini-circuitos comerciales circunscritos, observados y descritos por algunos antropólogos que trabajaron con los pueblos Pemón, Akawaio y Makuxi en los años sesenta y setenta del siglo XX, son apenas los fragmentos a los que el SIRO quedó reducido después de la militarización del Orinoco y del repliegue de los Kariña en el siglo XVIII.

En las décadas de explotación del caucho, un alto porcentaje de las poblaciones orinoquenses fue atrapada en las redes del régimen esclavista de explotación cauchera, hubo reclutamiento compulsivo de mano de obra indígena, ocurrieron dislocaciones demográficas, alteraciones en los patrones de asentamiento y alta morbilidad en las poblaciones indígenas. Aunque no poseo datos directos y que abarquen el universo amazónico-orinoquense, no es especulativo postular que el impacto del ciclo del caucho debe haber sido tan grave y fuerte como lo fue la militarización del Orinoco durante el siglo XVIII, cuando los Kariña diezmados por enfermedades y bajas en el enfrentamiento armado decidieron huir o reducirse a misiones. Ambos fenómenos obviamente influyeron negativamente en la configuración del Sistema de Interdependencia Regional del Orinoco.

La era del caucho fue reemplazada una década más tarde por la refundación de misiones católicas y, eventualmente, también por la entrada de misiones evangélicas. Las misiones abrieron el camino y las rutas de penetración a los futuros invasores y acaparadores de tierras jurídicamente baldías, pero tradicionalmente indígenas. A esas nuevas invasiones los indígenas respondieron de manera militante en el albor de los años setenta del siglo XX. En esa época inicié mis estudios etnográficos y pude hacerle seguimiento a los movimientos etnopolíticos protagonizados inicialmente por los Yekuana o Dekuana del Amazonas.

\section{Movimientos etnopolíticos en la Región Sur de la cuenca del Orinoco}

Desde 1971 he sido testigo, además de analista, de las luchas contemporáneas de las etnias indígenas orinoquenses para reivindicar derechos territoriales y culturales directamente lesionados por las políticas públicas de carácter geopolítico, económico y ambiental de la Región Sur del país. La administración central implantó dichas políticas primero para la Región Sur entre 1969-1973, y después entre 1974-1979, 1985-1989 y durante la llamada apertura minera de 
1994 a 1998 para la Región Guayana, que es la misma región pero que cambió de nombre. Todas estas políticas han tenido una incidencia negativa para los intereses, necesidades y derechos indígenas. Lo que parece modificar cualitativamente el cuadro político es que los indígenas no han permanecido ni pasivos ni callados ante tales políticas. Producto de este choque de fuerzas entre intereses de Estado y derechos indígenas se desencadenó en el sur del Orinoco un tenso juego de fuerzas que enfrenta, de un lado, a especuladores y colonos en busca de tierras junto con mineros "criollos", quienes interpretan las políticas públicas según sus intereses, y, del otro lado, las poblaciones autóctonas que reivindican derechos territoriales y culturales mediante diversas estrategias de oposición y resistencia. Las políticas públicas destinadas a consolidar la presencia de los entes del Estado han estado acompañadas de un flujo migratorio de técnicos y profesionales "criollos" que llegan al Sur para fundar, reforzar o expandir los servicios sociales de salud, educación, carreteras y comunicación, y, mediante la puesta en marcha o funcionamiento de los mismos, interfieren directamente en la relativa autonomía cultural y política que los indígenas que no fueron sometidos a las misiones disfrutaron durante algunas décadas del siglo XX.

En 1971 irrumpió una movilización etnopolítica protagonizada por indígenas yekuana habitantes del río Ventuari, en el Territorio Federal Amazonas. Estos yekuana recibieron el apoyo del resto de las regiones o bloques políticos yekuanas y dekuanas ubicados en el río Caura, del estado Bolívar y en el alto Orinoco en el estado Amazonas. En esta crisis, los descentralizados yekuanas se unieron en una sola voz de protesta (Arvelo-Jiménez, 2000) y esta última, que comenzó teniendo al Amazonas como escenario, alcanzó una proyección nacional poco después. El detonante de la protesta fue la invasión de parte del territorio ancestral yekuana por una compañía formada por extranjeros y criollos que estaba estimulada por la pretensión de la administración central de poblar y colonizar las áreas fronterizas con Colombia, Brasil y Guyana mediante "la Conquista del Sur”. Estas áreas eran calificadas como áreas desprotegidas, vacías en términos geopolíticos, y como marginales al desarrollo económico del resto del país. Por su parte, los criollos y extranjeros invasores estaban alucinados con la imaginada panacea de riquezas minerales, madereras y de tierras baldías que esperaban ser apropiadas. En realidad, estos autodenominados empresarios del Sur demostraron que carecían de un proyecto económico con proyección regional.

La protesta yekuana adquirió una fuerza arrolladora y expansiva, potenciada, quizás, por el máximo uso que hicieron los Yekuana de los medios de comunicación masiva. Su resonancia local de repudio constituyó un gran estímulo para que la protesta indígena de solidaridad con los Yekuana se manifestara 
abiertamente en otras etnias del Sur y del resto del país. Esta movilización de la opinión pública, a lo largo de tres meses ininterrumpidos, abrió a los indígenas un espacio o canal político de interlocución con la opinión pública nacional y con el poder ejecutivo. Su impacto nacional forzó al gobierno a entablar una pretensión de diálogo con los indígenas. El potencial de esta apertura política sufrió, sin embargo, un serio revés debido a que la protesta yekuana era muy específica y entendida por ellos como de rápida resolución. Cuando los Yekuana se retiraron a sus comunidades, ascendieron algunos dirigentes indígenas dispersos que no constituían una organización y, por ende, no estaban preparados para enfrentar organizadamente las artimañas que les presentó la maquinaria política del Estado. Esta condición de "communitas" facilitó al Gobierno tomar la iniciativa de organizar un movimiento indígena decretado. Nacieron las federaciones indígenas estaduales promovidas desde la cúspide del poder criollo. Estos novísimos dirigentes indígenas, organizados artificialmente por técnicos de instituciones gubernamentales en movimientos interétnicos estaduales, se convirtieron en los únicos interlocutores oficiales reconocidos por el Estado y, a través de ellos, el gobierno logró en escasos meses que aceptaran sumarse al programa de dotación de tierras diseñado en Caracas por los técnicos del Instituto Agrario Nacional (IAN). Ese diseño estaba obviamente enmarcado dentro de las pautas de la Ley de Reforma Agraria de 1961 y contenía una triple estrategia: (i) dotaciones colectivas de tierras según las cuales al ser considerados como campesinos, los indígenas recibirían fragmentos del territorio étnico ancestral; (ii) micro-empresas económicas agropecuarias; y, (iii) federaciones interétnicas a nivel de cada estado con pueblos indígenas reconocidos como tales por empleados gubernamentales (Arvelo-Jiménez, 1980; Arvelo-Jiménez \& Perozo, 1983). Transcurrieron 22 años, período durante el cual los indígenas estuvieron aguardando los ansiados títulos definitivos de propiedad colectiva de sus tierras, así como la clarificación de la ambigüedad jurídica sobre la propiedad indígena de las tierras ancestrales que los rodeaba y que tanto les preocupaba. Entre tanto, el avance de las fronteras internas expresado en una serie de acontecimientos políticos y económicos adversos a los derechos de los pueblos indígenas adquiría cada vez mayor fuerza. Los Yekuana del estado Amazonas nuevamente señalizaron su impaciencia y desconfianza, y una actitud de repudio y rebeldía cuando, en 1993, decidieron emprender un proceso de auto-demarcación de sus tierras ancestrales, significando con este acto de soberanía local y autonomía cultural que habían asimilado la falsedad de la promesa gubernamental de los años setenta, a la vez que comprendían que la resolución de la ambigüedad legislativa de sus derechos territoriales tenía que pasar a manos indígenas, quienes eran los 
directamente afectados, e implementar una lucha reivindicativa más proactiva (Jiménez \& Perozo, 1994).

La indefensión jurídica en la que permanecían los indígenas fomentó la aparición de juicios negativos acerca de la oportunidad política perdida en los 22 años transcurridos, afirmándose en contextos indigenistas públicos y privados que los indígenas habían permitido la desaparición del capital de negociación política ganado años antes por los Yekuana para ellos mismos y para todos los indígenas. Esta misma impresión de pérdida era manifestada por antropólogos, politólogos y otros analistas externos que no lográbamos hallar en los múltiples esfuerzos indígenas de resistencia una trayectoria sistemática y acumulativa de planteamientos, metodologías o modalidades de lucha y de resultados concretos para la reivindicación territorial, bandera y eje central de la movilización reivindicativa. Como antropóloga que seguía de cerca las actividades de resistencia cultural alcanzadas por los Yekuana, Kariña y Pemón durante el período en cuestión, me preocupaba no haber generado una respuesta propia que explicara la lógica de la resistencia indígena en Venezuela y que refutara las aseveraciones y comentarios de colegas expertos en movimientos etnopolíticos de países andinos y mesoamericanos, en las cuales insinuaban que en Venezuela las movilizaciones indígenas no tenían ni organización ni lógica y que las llamadas luchas indígenas no pasaban de ser manifestaciones aisladas, sin coordinación ni coherencia que las unificara, centralizara e imprimiera sentido.

En 1998 rememoré las características estructurales y funcionales del SIRO que yo misma había interpretado como el marco político para las relaciones interétnicas de las sociedades indígenas habitantes de la cuenca del Orinoco y que postulé a partir del modelo de lucha exitosa por varios siglos implementado por el pueblo Kariña contra los españoles. Pude vislumbrar la racionalidad de las luchas indígenas contemporáneas y estuve en capacidad de discernir que el mayor obstáculo para aprehenderla había sido el modelo organizativo que esperábamos hallar, es decir, el de una estructura vertical centralizada bajo un solo mandato, algo así como el deber ser de una lucha política moderna y contemporánea. Desfilaron ante mí otras interferencias, que como analistas externos mezclamos en nuestros análisis de los otros, como cuando utilizamos un criterio temporal arbitrario como la división de la resistencia indígena en cortos períodos llamados décadas. Debido a estos prejuicios, inferíamos un cuadro desolador de fracasos, desarticulación y desencuentros. Ahora creo entender el ritmo y naturaleza de la protesta y de la lucha indígena. Mi paralización de años se debió al sesgo que yo misma introduje con un abordaje atomizado, en vez de haber sido consecuente con el marco político que propuse en el SIRO para la etnología orinoquense. De 
allí pude concluir que la horizontalidad de las relaciones entre pueblos indígenas orinoquenses no ha dejado de existir, que el trayecto temporal de los movimientos políticos "criollos" puede ser susceptible de un tratamiento temporal por fracciones arbitrarias llamadas décadas puesto que, como afirma el intelectual maya Pop Caal, el ladino en la búsqueda de sus raíces histórico culturales no puede ahondar sino apenas 400 o 500 años de historia ya que carece de las raíces milenarias de las civilizaciones indias. Debido a este abordaje tan sesgado por las concepciones temporales que adoptamos de los europeos y por nuestra manera de pensar lo político, es que los triunfos y reivindicaciones obtenidos por los indígenas parecían diluidos y desperdiciados en el vasto horizonte espacial de la cuenca del Orinoco, como producto de una militancia dispersa y desorganizada formada por grupos, federaciones y facciones de los movimientos indígenas que trabajan ineficientemente, sin coordinación y sin un proyecto común.

Algunos de los triunfos y victorias políticas acumuladas por los indígenas y que anteriormente percibí como desconectados y fortuitos, son:

1 - La apertura simultánea de un canal de interlocución entre el Estado y los pueblos indígenas, y entre estos y la opinión pública nacional, que treinta años después ha dado resultados positivos para los movimientos etnopolíticos.

Este canal de interlocución atravesó un accidentado camino de experimentos de cooptación política de parte de la Administración Central (CODESUR, IAN, CIARA, OMEFI Y OMAFI, PRODESUR, CVG y EDELCA, entes del poder ejecutivo), de los gobiernos estaduales, de los partidos políticos más populares, principalmente Acción Democrática o Social Demócrata, conocido por su siglas AD, el social cristiano COPEY, el Movimiento al Socialisto o MAS, La Causa Radical o CAUSA R, y de Patria para Todos o PPT. Ante el menguado éxito de los partidos políticos, también algunas órdenes religiosas (Jesuitas y Salesianos) intentaron controlar la fuerza política de las etnias indígenas y ganaron poder relativo en el estado Amazonas, como analizaré más adelante. Finalmente, a mediados de los años noventa (1994-1998) del siglo XX, irrumpió en el escenario de las luchas indígenas una coordinadora criolla compuesta por ambientalistas e indigenistas. Esta coordinadora que operó en la Región Guayana (estados Delta Amacuro, Bolívar y Amazonas) logró capitalizar el descontento indígena por las políticas públicas inconsultas que los afectaban directamente sin que se hubieran resuelto las viejas y tradicionales reivindicaciones de la causa indígena por las tierras ancestrales. Esta coordinadora logró igualmente proyectar este descontento regional a nivel nacional, ya que dichas políticas públicas de desarrollo 
económico, lejos de apuntalar una reforma estructural de la economía venezolana, pretendían continuar favoreciendo la extracción petrolera, aurífera y maderera por parte de las grandes transnacionales. Esta coyuntura permitió la forja de una alianza entre varias tendencias de la izquierda venezolana y el movimiento militar insurgente de Hugo Chávez Frías, llamado Movimiento Revolucionario MBR 2000. Los movimientos de izquierda habían poseído cierta relevancia política durante los años sesenta del siglo XX, cuando practicaron guerra de guerrillas, pero, derrotados unos y pacificados otros, habían logrado sobrevivir en las márgenes del poder como fragmentos diezmados y enemistados entre sí (Partido Comunista o PC, Unión Radical Democrática o URD, Movimiento al Socialismo o MAS, Movimiento Electoral del Pueblo o MEP, y Patria Para Todos o PPT). Por su lado, el apoyo civil de los grupos de izquierda al Movimiento Revolucionario MBR 2000 prestó la fachada civil y democrática que Chávez Frías necesitaba para poder competir por la presidencia de la República dentro del sistema político venezolano.

Por su lado, el movimiento etnopolítico indígena, con 28 años de trayectoria, saboreó reveses causados por haber aceptado esquemas criollos de desarrollo económico así como haber concertado alianzas con entes criollos, y por divisiones internas desgastantes y despilfarradoras del espacio político que los Yekuana habían abierto a comienzos de los años setenta del siglo XX. Pese a estas adversidades, los dirigentes indígenas, a través de dos generaciones, lograron mantener abierto el canal político y estuvieron en capacidad de celebrar elecciones primarias que permitieron a seis dirigentes indígenas convertirse en constituyentes y co-redactores de la Constitución Bolivariana de Venezuela, aprobada en diciembre de 1999, la cual contiene un capítulo de ocho artículos directamente relacionados con los derechos indígenas. Algunos de estos constituyentes indígenas optaron a diputados de la Asamblea Nacional y resultaron victoriosos en esas elecciones, siendo ahora miembros de la Asamblea Nacional dentro de la cual forman una fracción especializada en asuntos indígenas. Esta conquista ocurre por primera vez en la historia republicana.

Al principio de este proceso de treinta años aquellas federaciones indígenas, inventadas por la administración central resultaron ser, en la práctica, entelequias multiétnicas creadas para que los indígenas vivieran la ficción de poseer un canal directo de comunicación con el Estado, y no cumplieron la vocación reivindicativa que pudieron haber tenido debido a que funcionarios indigenistas las vincularon al partido político de turno en el poder. Sin embargo, las generaciones subsiguientes no permitieron que muriera ese reconocido espacio político. Mientras los indígenas tuvieron la ilusión de disponer de un mecanismo 
político, los funcionarios indigenistas "partidizaron” su gestión reivindicativa mediante la manipulación de sus dirigentes, cuyos miembros fueron incitados a competir según las diferentes concepciones partidistas que tenían pautas para resolver las relaciones Estado/Indígenas. Esa rivalidad partidista neutralizó su ya escaso potencial político, aunque el saldo fue una mayor pugnacidad entre dirigentes indígenas y pocos resultados concretos inmediatos. Los indígenas aprendieron la amarga lección del limitado potencial de las luchas etnopolíticas, ideadas, dirigidas y subsidiadas desde arriba, por el Gobierno. Prueba de que la lección fue asimilada es que la pequeña hoguera de rebeldía y protesta indígena continuó extendiéndose a otras generaciones de jóvenes indígenas urbanos, quienes en los años ochenta formaron varios movimientos políticos y los conectaron con los movimientos indígenas e indigenistas internacionales. Ejemplos actuales son el Movimiento Indígena de Guayana (MIG) que ha sobrevivido y continúa cumpliendo con vigor su papel reivindicador de los derechos indígenas a la vida y a la tierra, la ORPIA u Organización de Pueblos Indígenas del Estado Amazonas, y la CONIVE, Coordinadora Nacional de Indígenas de Venezuela, que fue aceptada desde 1988 como coordinadora nacional de los movimientos locales y regionales. En otras palabras, la generación de líderes tradicionales intraétnicos espontáneos, monolingües o con precarios conocimientos del español, cuya emergencia forzó la defensa de las tierras ancestrales, fue sucedida pero no reemplazada por una generación de jóvenes con educación formal, conexiones políticas nacionales y con vínculos internacionales con ONGs dedicadas a la defensa de los derechos colectivos de los pueblos indígenas. Aunque en un principio estas dos generaciones se enfrentaron como si fueran redundantes y aunque no se han borrado todos los recelos de lado y lado, el transcurrir de varias décadas demuestra que cada generación ha cumplido y cumple papeles y tareas diferentes y complementarias que enriquecen la lucha indígena y la hacen extremadamente compleja.

2 - La promulgación del Decreto No 283 sobre el Régimen de Educación Intercultural Bilingüe (REIB) en 1979.

La brecha entre pueblos indígenas y opinión pública nacional que estaba respaldada por la ignorancia de los criollos sobre los indígenas y por la invisibilidad que sobre ellos mantenía la historia oficial, la educación pública formal y la carencia de una masa crítica de historiadores y antropólogos con afanes alternativos por encontrar las raíces culturales e históricas de Venezuela, fue lentamente sustituida desde los comienzos de los años setenta por la incidencia de varios 
fenómenos políticos que chocaron e hicieron confluir a indígenas del Sur y de las áreas fronterizas con pobladores criollos de las zonas urbanas del Norte del país. Como resultado de la conjunción de fuerzas y presiones ejercidas conjuntamente sobre el Ejecutivo Nacional por indigenistas, lingüistas y dirigentes indígenas se logró el establecimiento del REIB para los tres primeros años de educación primaria y para nueve idiomas indígenas. Esta iniciativa estimuló al resto de los pueblos indígenas para reclamar para sí la aplicación del REIB a sus culturas e idiomas. Asimismo, fomentó indirectamente una producción muy copiosa de literatura indígena, cuyas expresiones más comunes son textos bilingües sobre la historia cultural de cada etnia. Algunos de estos textos son libros de referencia para los maestros bilingües y fueron auspiciados oficialmente por el Ministerio de Educación, en tanto que el resto de la producción literaria e histórica indígena contemporánea ha sido escrita al margen de todo auspicio oficial gracias al empeño de maestros y otros intelectuales indígenas ansiosos por contribuir para mantener las culturas de sus pueblos. También, otros indígenas entusiasmados por lo que interpretan como un ambiente sociopolítico favorable hacia ellos y hacia la creación y expresión cultural, han creado programas propios de pedagogía aborigen que buscan crear antídotos culturales contra el impacto de la educación formal impartida en las escuelas públicas. Tal es el caso del programa coordinado por Filintro Yavina en San Carlos de Río Negro y Maroa (Silvia Vidal, comunicación personal 1997) y la Escuela Aramare en la aldea Mawadi Anäjödönña en el rio Cunucunuma, ambos del estado Amazonas.

3 - La respuesta indígena a una nueva colisión entre los intereses económicos de Estado y los requerimientos o Plan de Vida de los pueblos indígenas anclados en el control de sus tierras ancestrales y de los recursos naturales en ellas alojados

La severa crisis de la petro-economía venezolana se agudizó con la interrupción del período constitucional del presidente Carlos Andrés Pérez y con el año de interinato del senador R.J. Velázquez, quien interrumpió el plan económico de restructuración económica. La administración subsiguiente abrió las puertas de la economía nacional a la inversión financiera internacional y a las transnacionales, e inició la descentralización de la administración pública con el objeto de minimizar el tamaño de la burocracia del Estado. Las transnacionales por varias décadas aguardaron esta apertura que estaba centrada en los recursos naturales de la Región Guayana y esencialmente estaban interesadas en el petróleo del Delta Amacuro y de la Faja del Orinoco, así como en las grandes reservas de oro alojadas en tierras de los Pemón y de otros grupos indígenas habitantes 
del estado Bolívar. De allí que la mencionada apertura llevó al poder ejecutivo a favorecer la instalación de empresas mineras de gran escala en detrimento de los pequeños mineros del oro, tanto criollos como indígenas. La pequeña minería fue declarada ilegal y destructiva, perjudicando a contingentes de migrantes criollos que habían encontrado refugio en actividades de pequeña minería, aliviando la condición de los desempleados desplazados por el estancamiento y la depresión económica en las áreas urbanas. Igualmente, la apertura exigía la desafectación de áreas congeladas como áreas bajo el régimen de administración especial (ABRAE). Ofensa sobre ofensa para el pueblo Pemón que había luchado tan denodadamente por la reivindicación de sus tierras ancestrales y que ahora era la víctima privilegiada de la apertura minera junto con los indígenas Warao del Delta del Orinoco.

Un problema emblemático de los rigores a los que la política gubernamental sometió a los pueblos de la Región Guayana, lo representa la crisis que se desató en torno a la desafectación del área protegida conocida como Reserva Forestal de Imataca que hizo crisis en 1997. La Reserva de Imataca, ubicada en el nordeste del estado Bolívar fue rezonificada por el decreto ejecutivo No. 1850 de 1997. Además de la injuria a los Pemón, este acto del Poder Ejecutivo nacional era revocado por haberse arrogado una competencia que constitucionalmente le pertenece al Poder Legislativo. Se integraron a la protesta los movimientos indígenas de los estados Bolívar y Delta Amacuro, miembros de ONGs ambientalistas y defensoras de los derechos humanos, movimientos estudiantiles, profesionales universitarios, y abogados constitucionalistas, quienes ejercieron presión ante la Comisión de Ambiente del Senado para que ésta a su vez elaborara una demanda de impugnación del Decreto 1850 ante la Corte Suprema de Justicia. El Movimiento Revolucionario Bolivariano con Hugo Chávez como candidato a presidente se montó en la ola de la protesta al adherirse a la posición que pedía la abolición del decreto 1850 .

En 1998, último año de gobierno de la desacreditada administración Caldera y, por ende, año de la campaña electoral presidencial, la crisis de Imataca creció al hacerse público el convenio acordado por los presidentes de Venezuela y Brasil, realizado a espaldas de la opinión pública y, peor aún, de las poblaciones residentes en la Gran Sabana del estado Bolívar, acerca del impacto ecológico de la construcción de torres de alta tensión para surtir de energía eléctrica a los norteños estados brasileros de Roraima y Amazonas. Los Pemón, hartos de la ineficiencia de sus tácticas institucionales y pacíficas de protesta, recurrieron a la toma y bloqueo de la carretera ElDorado-Santa Elena de Uairén, que se comunica con Boa Vista, en Brasil. Este bloqueo fue disuelto en varias oportunidades 
mediante la intervención conciliadora de autoridades y personalidades de la sociedad civil, pero los Pemón debieron hacer frente a la represión ejecutada por la Guardia Nacional. La campaña electoral que culminó en diciembre de 1998 forzó una pausa en esta dura lucha que enfrentaba a indígenas y militares. Los indígenas de todo el país, incluyendo a los Pemón, creyeron que un gobierno revolucionario, sin conexiones con los cuadros político-económicos corruptos que prosperaron y se enquistaron en la administración pública durante los últimos 40 años, constituía una esperanza diferente de todas las promesas que le habían ofrecido durante aquellos 40 años de democracia. Votaron en masa por el Movimiento V República y aguardaron los primeros pasos de la nueva administración.

La lucha de los Pemón en Bolívar se reanudó después de varios meses de gestión gubernamental de Chávez, durante los cuales una Ministra del Ambiente y de los Recursos Naturales no Renovables, de estirpe indígena Wayúu, nada logró concretar ni sobre el revocado decreto 1850 ni sobre la suspensión de la construcción de las torres de alta tensión. La resistencia pemón forzó al Presidente a colocar como negociador al propio vicepresidente de la República, quien logró convencer a la mitad de la dirigencia pemón para que aceptaran el status quo sin que hasta el momento haya cambiado nada a favor de la reivindicación territorial pemón!

Hoy en día, la otra mitad del pueblo pemón continuó saboteando la erección de las torres, tumbando varias de ellas. No obstante, la balanza del poder político se ha inclinado a favor de los que tienen el control de la represión física y de las armas, el Estado venezolano. El tendido eléctrico ya fue inaugurado y surte de energía a Roraima. El desenlace de esta historia de resistencia está aún por ocurrir.

4 - El Movimiento Etnopolítico en el estado Amazonas (1990-2001)

La trayectoria de los movimientos etnopolíticos en el estado Amazonas ha sido un tanto diferente de la que han seguido los otros pueblos indígenas del país desde 1988, año de la fundación de la Coordinadora Nacional CONIVE. Los pueblos indígenas del Amazonas desconfían mucho de la centralización y la integración en un eje vertical de poder único. De allí que al CONIVE le ha sido extremadamente difícil penetrar al interior de las aldeas y regiones del estado Amazonas, y la conexión que ha logrado fortalecer ha sido con el movimiento regional llamado ORPIA, cuya única sede está en la capital del estado, la ciudad de Puerto Ayacucho. Otra diferencia es que no existe ni explotación de petróleo ni de oro, pues la minería del oro es furtiva y de pequeña escala y no está 
públicamente abierta a las grandes compañías transnacionales. No obstante, los problemas que enfrentan los Pueblos indígenas amazónicos no son menos graves:

a) el poder interventor de la iglesia católica es fuerte y muy vigente. La Iglesia maneja en gran parte el destino político de la mayoría de los indígenas a través de los servicios que desde los años ochenta del siglo XX ofrece su oficina por la defensa de los derechos humanos. Igualmente, a través de la organización ORPIA, la Iglesia Católica procuró y consiguió los fondos internacionales decisivos para su fundación y operatividad.

a) prevalecen los antiguos prejuicios coloniales que descalifican al indígena como incapaz, ignorante y carente de la fuerza, ambición y creatividad para transformar la economía del estado Amazonas para articularla al ritmo de la economía capitalista globalizada.

a) la división político-administrativa de este estado, vigente desde 1992, lejos de haber facilitado el traspaso del poder local y la entronización del autogobierno a la mayoría indígena a través de la administración de los siete municipios que fueron creados en ese año, se ha tornado en punto de discusión encarnizada entre, principalmente, dos bandos: el grupo de dirigentes indígenas controlados por la Iglesia a través de la organización interétnica ORPIA, y otros dirigentes indígenas y sus seguidores que ni tienen ni desean tener padrinos políticos ni patrocinadores religiosos y todo lo que aspiran es a mantener una independencia que les permita la revitalización de sus culturas y la toma de decisiones propias. Esta división entre indígenas no ha podido ser completamente superada durante los últimos ocho años y ya pasó en sus comienzos por un proceso jurídico de impugnación de la ley de división político-territorial adelantado por los abogados de ORPIA ante la Corte Suprema de Justicia. Estas diferencias han sido ampliamente aprovechadas por los políticos criollos para usurpar el poder que la ley otorgó a los indígenas para continuar así manejando su destino a través de líderes indígenas corruptos.

Este revés moral y político causó profundas perturbaciones en el entusiasmo de muchos indígenas amazonenses, quienes hasta la promulgación de la Constitución Bolivariana habían desacelerado el ritmo e intensidad de las luchas reivindicativas por la tierra. 
No obstante, fue en el estado Amazonas donde comenzó en 1993 una lucha de resistencia diferente a las que yo había observado hasta entonces; nueva, en el sentido de no esperar más que la solución del problema de tierras viniera del Gobierno sino con carácter más proactivo y pionero. La formularon los Dekuana de los ríos Cunucunuma, Padamo y Cuntinamo, en el alto Orinoco, mediante un proyecto de auto-demarcación de su territorio ancestral (Jiménez \& Perozo, 1994; Arvelo-Jiménez y Conn, 1995).

Varias características en esta etnopolítica la distinguen y la convierten en punto de inflexión dentro de las estrategias que han puesto en práctica los Yekuana, en particular, y otros indígenas, en general. Se continúa y reitera la reivindicación de la tierra ancestral como eje de la movilización política, pero en este caso los Yekuana o Dekuana deciden realizar ellos mismos el trabajo más costoso y difícil de la delimitación en-tierra, demarcando físicamente los hitos estratégicos a lo largo de los linderos de su territorio. Primero, se reúnen varias aldeas para discutir y recordar colectivamente cómo fue la primera demarcación territorial realizada por el demiurgo Kuyujani, en tiempos inmemoriales. Kuyujani deslindó el territorio que le legó en custodia a los Yekuana. Segundo, con base en las discusiones, se dibujan mapas semánticos del territorio y, sobre el que se aprueba como más exacto, se establece la metodología de la demarcación física. Después, dividen el trabajo en seis equipos de 32 personas cada uno; a cada equipo le toca delimitar parte de ese territorio entregado por Kuyujani, quien antes de salir de la dimensión terrestre promete que en cualquier momento regresará a la tierra. Para honrar la memoria de esta profecía, el proyecto se denomina informalmente Esperando a Kuyujani, apelativo que fue conservado hasta que fue necesario imprimirle personalidad jurídica a esta primera iniciativa de auto-demarcación en Venezuela. Desde entonces, se creó la organización civil que integran 17 aldeas yekuana y que se registra junto con sus estatutos bajo el nombre de Kuyujani Originario.

Dando continuidad a la demarcación física, se detectan desde el aire los hitos demarcados por los equipos en tierra y se registran mediante el GPS en un primer mapa físico muy elemental, que destaca la ubicación de cada uno de ellos dentro de coordenadas geográficas y de las aldeas que participan del Proyecto. Se sigue el proceso con el adiestramiento que recibió un grupo de yekuanas que aprendieron a manejar el GPS para facultarlos para ampliar la información que contiene el mapa definitivo. Este mapa se entregará a la Comisión de Delimitación de Tierras y Hábitats Indígenas junto con el reclamo territorial.

Trabajos con OTRO FUTURO (la ONG que apoya técnicamente a Kuyujani Originario) en el marco jurídico más apropiado para acompañar el reclamo 
territorial yekuana tuvieron un frustrante resultado porque la Constitución Venezolana vigente hasta 1999 no facilitaba una conclusión convincente y satisfactoria para el caso Yekuana. Esto quiere decir, entre otras cosas, que la iniciativa de este pueblo se adelantó en más de un lustro a los cambios políticos y jurídicos que sólo ocurrieron en Venezuela a finales de 1999. Entre tanto, se enriqueció la información del mapa levantado por cinco técnicos yekuanas con la ayuda del geógrafo Domingo Medina y se pudo terminar el mapa del territorio y los recursos naturales alojados en sus tierras en junio del 2001.

Este ejemplo de auto-demarcación comenzó a ser copiado y emulado a partir de 1996 por el bloque político yekuana del río Caura en el estado Bolívar y además contagió, con entusiasmo y esperanza, a otros pueblos indígenas amazónicos como los Piaroa y los Yabarana. Este impacto inicial, que luego en el 2001 ya tenía una repercusión en varios otros pueblos indígenas de la cuenca del Orinoco y del país, era un efecto esperado por los indígenas de la Asamblea de las Naciones Originarias del Canadá, quienes intermediaron con financiadoras canadienses para conseguir los recursos iniciales que permitieron el trabajo de los seis equipos yekuana de auto-demarcación. Se proporcionó un nuevo horizonte de combate por el derecho a las tierras ancestrales.

\section{Discusión y perspectivas presentes y futuras}

Estimo que uno de los principales resultados es el de haber detectado el pulso y ritmo genuinos inherentes a los cambios acometidos por los indígenas y haber podido rastrear las huellas del SIRO más allá de su época de fuerza en el siglo XVIII, es decir, su sobrevivencia y posteriores modificaciones causadas por el impacto colonial y republicano en el siglo XIX y hasta mediados del siglo $\mathrm{XX}$, donde pervive reducido a fragmentos muy localizados con acción limitada entre los pueblos que sobreviven en la citada cuenca. Igualmente importante es entender cómo estos pueblos indígenas contemporáneos, tan marcados y atropellados culturalmente por la evangelización, la educación formal y la intrusión de agentes de cambio y portadores de violencia, todavía respetan y practican la horizontalidad en las relaciones interétnicas en su accionar político, mientras evaden la jerarquización vertical en un solo movimiento etnopolítico con idénticos métodos e iguales mecanismos de lucha. El futuro de la acumulación y confluencia de poder en un pequeño círculo de dirigentes indígenas convertidos por el poder del voto en diputados a la Asamblea Nacional, disfrutando de una amplia capacidad de decisión y presión, hecho inédito en la vida pública venezolana, es un enigma sin respuesta a corto plazo. Podría ser que somos testigos de una centralización y verticalización temporal a guisa de los jefes militares kariña 
en los siglos XVI y XVII. Está por demostrarse cómo funcionará la centralización de poder en las entrañas de la maquinaria política criolla y necesariamente acompañada y entremezclada con tácticas políticas criollas.

Esta investigación también ha reiterado la ocurrencia de la afirmación hecha por Morales Méndez en 1979 cuando expresó que la historia de América, desde la llegada de los europeos, no es una historia de dos vertientes paralelas, las tradiciones culturales europeas y las tradiciones culturales indígenas, sino que ambas están inextricablemente y complejamente imbricadas o unidas como las dos caras de una misma moneda. Durante las décadas y siglos analizados, en los cuales a pesar de las transformaciones en las culturas indígenas, éstas han logrado sobrevivir hasta hoy día experimentando procesos de fragmentación y reconstitución étnicas, guardando una estrecha relación con la cultura de los criollos con los que mantienen hasta ahora relaciones constantes de tensión y diálogo. Si lográramos una mayor abundancia de datos por un mayor número de investigadores, ello nos conduciría a erradicar concepciones eurocéntricas que califican a los pueblos latinoamericanos como pueblos jóvenes y al criollo como huérfano de raíces milenarias, y a las formaciones sociales indígenas como bandas sin organización ni sistemas políticos ni historia, lo cual es equivalente al limbo histórico inventado para facilitar y excusar la subyugación y el dominio de nuestros antepasados.

Se abre la perspectiva de encarar el fenómeno de la continuidad cultural de frente a los procesos de cambio y lo que cada proceso realmente significa dentro del hilo histórico y cultural que ata a los pueblos indígenas en contacto y transformación con los elementos formativos de la cultura criolla, y la falaz oposición entre criollo e indígenas. Investigaciones como éstas nos harían aprehender la estructura profunda y el significado de los movimientos etnopolíticos recientes y su conexión con las etapas proto-colonial y post-colonial de nuestra historia. De ello aprenderíamos a escuchar el pulso y el ritmo de nuestra propia formulación de proyectos políticos propios.

También incita a la reflexión sobre el potencial de adentrarnos en los niveles profundos de la resistencia cultural y de los mecanismos sutiles que expresan la continuidad. Bajo esta perspectiva las luchas indígenas no han sido ni estériles ni aisladas. Esto ilumina de una forma diferente las manifestaciones que en recientes décadas han hecho "criollos" que se autodenominan descendientes de indios guayqueríes, chaymas, kariñas, cumanagotos, píritus, mapoyos y yabaranas, y que analistas externos hemos llamado "neo-chaymas", "neo-kariñas", "neo-guayqueríes”, etc. Estas manifestaciones están ocurriendo cada vez con 
mayor frecuencia en el contexto o canal de interlocución que existe en Venezuela entre Estado, opinión pública criolla e indígenas.

También luce necesario intentar entender la emergencia silenciosa de esta revitalización cultural de poblaciones indígenas y la re-indianización explícita de poblaciones campesinas y de profesionales criollos de clase media. La resistencia y la re-indianización se han producido sin manipulación externa y como producto de un proceso originado en la base, desde niveles profundos hacia los niveles más visibles y fáciles de aprehender, y de forma horizontal, es decir, sin una coordinación centralizada y única, como hubiera sido un movimiento vertical dirigido desde arriba. No obstante, esta horizontalidad no ha descuidado contar con representantes a nivel central ni jugar con la conjunción de lo horizontal y lo vertical, lo indígena y lo criollo.

Finalmente, esa misma mirada o abordaje telescópico (Arvelo-Jiménez, 1979), de largo período (Carrera Damas, 1984) o de larga memoria (Rivera Cusicanqui, 1986), también colma de significado los debates acerca de la identidad nacional o sobre "la dificultad de ser criollo", dilema no resuelto ni por el criollo venezolano ni por el latinoamericano pese el intento de múltiples definiciones del criollo. Esto pone al descubierto la naturaleza imaginada del Estado como nación una y exenta de diversidad cultural, étnica o lingüística, modelo calcado del Estado nación europeo.

Recebido em: 28 de agosto 2014

Aceito em: 02 de outubro de 2014

Nelly Arvelo-Jiménez é Antropóloga da Universidade Central de Venezuela (1963) e PhD em Antropologia de Cornell University (1971). Pesquisadora Emérita e professora do Instituto Venezolano de Investigaciones Científicas (IVIC). É autora dos livros Political Relations in a Tribal Society: a Study of the Ye'cuana Indians of Venezuela (1971), Relaciones políticas en una sociedad tribal: estudio de los Ye'kuana, indígenas del Amazonas Venezolano (1974) e de inúmeros artigos sobre temas relacionados com os povos indígenas da Venezuela, em especial a história do sistema de intercâmbio do Alto Orinoco. Além da sua carreira acadêmica, tem uma longa trajetória de engajamento político junto com os movimentos indígenas venezuelanos. 


\section{Referencias bibliograficas}

ARVELO-JIMÉNEZ, Nelly. 1971. Political Relations in a Tribal Society: a Study of the Ye'cuana Indians of Venezuela. Ithaca, N.Y: Cornell University. (Cornell University Dissertation Series, 31).

1974. Relaciones políticas en una sociedad tribal: estudio de los Ye'kuana, indígenas del Amazonas Venezolano. México: Instituto Indigenista Interamericano.

. 1979. "Una perspectiva analítica: la antropología en el caso Nuevas Tribus".

Ms. de una conferencia dictada en el Departamento de Antropología del IVIC en Caracas.

. 1980. "Development Programs among Indigenous Populations of Venezuela:

Background, Consequences and a Critique”. In: Françoise Barbira-Scazzocchio (ed.). Land, People and Planning in Contemporary Amazonia. Centre of Latin American Studies. (Occasional Publications, 3). pp. 210-221.

. 2000. "The Crises in the History of Yekuana Cultural Continuity”. Etnohistory, 47(3-4):731-746.

ARVELO-JIMÉNEZ, Nelly \& BIORD CASTILLO, Horacio. 1994. "The Impact of Conquest on Contemporary Indigenous Peoples of the Guiana Shield: the System of Orinoco Regional Interdependence”. In: Anna Roosevelt (org.). Amazonian Indians from Prehistory to the Present: Anthropological Perspectives. Tucson \& London: The University of Arizona Press. pp. 55-78.

ARVELO-JIMÉNEZ, Nelly \& CONN, Keith. 1995. “The Yekuana Self-Demarcation Process". Cultural Survival Quarterly, 18(4):40-42.

ARVELO-JIMÉNEZ, Nelly \& MORALES MÉNDEZ, Filadelfo. 1981. "Hacia una estructura social caribe”. América Indígena, 41(4):603-626.

ARVELO-JIMÉNEZ, Nelly; MORALES MÉNDEZ, Filadelfo \& BIORD CASTILLO, Horacio. 1990. "Repensando la historial del Orinoco". Revista de Antropología y Arqueología, 5(1-2):153-174.

ARVELO-JIMÉNEZ, Nelly \& PEROZO, Abel. 1983. "Programas de desarrollo entre poblaciones indígenas de Venezuela: antecedentes, consecuencias y una crítica”. América Indígena, 43(3):503-536.

BIGENHO, Michelle. 1996. "Imaginando lo imaginado: las narrativas de las naciones bolivianas”. Revista Andina, 14 (2):471-507. 
BIORD CASTILLO, Horacio. 1985. "El contexto multilingüe del Sistema de Interdependencia Regional del Orinoco”. Antropológica, (63-64):83-101.

BUTT, Audrey. 1973. "Intertribal Trade in the Guiana Highlands”. Antropológica, 34:1-70. CARRERA DAMAS, Germán. 1984. Una nación llamada Venezuela. México: Grijalbo.

COPPENS, Walter. 1972. "Las relaciones comerciales de los Ye'kuana del Caura-Paragua”. Antropológica, 30:28-50.

GluCKMAN, Max. 1965. Politics, Law and Ritual in Tribal Society. Chicago: Aldine.

HEINEN, Hans Dieter. 1992. "The Early Colonization of the Lower Orinoco and its Impact on Present Day Indigenous Peoples”. Antropológica, 78:51-86.

JIMÉNEZ, Simeón \& PEROZO, Abel (eds.). 1994. Esperando a Kuyujani: tierras ,leyes y autodemarcación. Encuentro de comunidades Yekuanas del Alto Orinoco. Caracas: Otro Futuro, GAIA, IVIC.

MANSUTTI RODRÍGUEZ, Alexander. 1992. "Hipótesis sobre el poblamiento en el Orinoco Medio en el período proto-histórico temprano”. Antropológica, 79:3-50.

MORALES MÉNDEZ, Filadelfo. 1979. Reconstrucción Etnohistórica de los Kari'ñas de los Siglos XVI y XVII. Tesis de Maestría, Instituto Venezolano de Investigaciones Científicas.

MOREY, Nancy. 1975. Ethnohistory of the Colombian and Venezuelan Llanos. Ph. Dissertation Series, University of Utah.

MOREY, Robert \& MOREY, Nancy. 1975. Relaciones comerciales en el pasado en los Llanos de Colombia y Venezuela. Caracas: Instituto Venezolano de Investigaciones Científicas.

MURRA, John. 1975. Formaciones económicas y políticas del mundo andino. Lima: Instituto de Estudios Peruanos. (Historia Andina, v. 3).

PÉREZ, Berta. 2000a. "Rethinking Venezuelan Anthropology: Colonial Transformations in Venezuela”. Ethnohistory, 47(3-4):513-533.

2000b. "The Journey to Freedom: Maroon Forebears in Southern Venezuela”. Ethnohistory, 47(3-4):611-634.

QUIJANO, Aníbal. 2000. "Colonialidad del Poder, Eurocentrismo y América Latina”. In: Edgardo Lander (org.). La colonialidad del saber: eurocentrismo y ciencias sociales. Perspectivas latinoamericanas. Caracas: FACES/UNESCO. pp. 281-349. 
RIVERA CUSICANQUI, Silvia. 1986. "Oprimidos pero no vencidos”: luchas del campesinado aymara y qhechwa de Bolivia 1900-1980. Ginebra: UNRISD.

SCARAMELLI, Franz \& TARBLE, Kay. 2000. "Cultural Change and Identity in Mapoyo Burial Practice in the Middle Orinoco, Venezuela”. Ethnohistory, 47(3-4):705-730.

SMITH, Robert Chase. 1995. Amazonia: economía indígena y economía de mercado. Lima: OXFAM/COICA.

STEWARD, Julian. 1948. Handbook of South American Indians. Washington: Smithsonian Institution. v. 3.

THOMAS, David. 1972. “The Indigenous Trade System of Southeast Estado Bolívar, Venezuela”. Antropológica, 33:3-17.

URBINA FLORES, Luis. 1979. Adaptación ecológico-cultural de los Pemón-Arekuna: el caso de Tuauken. Tesis de Maestría, Instituto Venezolano de Investigaciones Científicas.

VALDEZ, Alberto. 1971. Intento de análisis integral sobre el actual proceso de acaparamiento de tierras baldías, tradicionalmente indígenas en el Amazonas venezolano. Caracas: Primeras Jornadas de Desarrollo Rural en Venezuela.

VIDAL, Silvia. 1987. El modelo del proceso migratorio prehispánico de los Piapoco: hipótesis y evidencias. Tesis de Maestría, Instituto Venezolano de Investigaciones Científicas.

WHITEHEAD, Neil L. 1990. Los cacicazgos virtuales del Orinoco. Conferencia en el Departamento de Antropología del I.V.I.C.

1994. "The Ancient Amerindian Polities of the Amazon, Orinoco and the Atlantic Coast: a Preliminary Analysis of their Passage from Antiquity to Extinction”. In: Anna Roosevelt (org.). Amazonian Indians from Prehistory to the Present: Anthropological Perspectives. Tucson: The University of Arizona Press. pp. 35-54.

ZUCCHI, Alberta \& GASSON, Rafael. 1986. Análisis de la Organización del Sistema de Intercambio Indígena en los Llanos Occidentales. XXXVI Convención Anual de la ASOVAC, Valencia, Venezuela. 


\section{Resumo}

Este artigo focaliza na compreensão das características estruturais e funcionais dos movimentos indígenas da Venezuela que surgiram no cenário político do país e na mídia, protagonizados inicialmente pelos índios Yekuana, durante a década de 1990. A partir dos conhecimentos etnológicos sobre os povos que habitam a bacia do Orinoco, e tendo como referência a matriz cultural orinoco-amazonense, analisam-se as conexões entre esses movimentos indígenas contemporâneos e os movimentos de resistência militar dos séculos XVI, XVII e XVIII que encontram suas raízes no Sistema de Interdependência Regional Horizontal do Orinoco (SIRO).

Palavras chave: Yekuana. Sistema de Interdependência Regional Horizontal do Orinoco (SIRO). Movimentos indígenas. Venezuela

\section{Abstract}

This article attempts to understand the structural and functional features of indigenous movements in Venezuela that appeared in the country's political scenario and in the media during the 1990's. Initially, the Yekuana Indians were the major protagonists of these movements. From the ethnological record about the peoples of the Orinoco basin, and having as a reference the Orinoco-Amazonian cultural matrix, the article analyses the connections between these contemporary indigenous movements and the movements of military resistence of the $16^{\text {th }}, 17^{\text {th }}, 18^{\text {th }}$ centuries, which have their roots in the Orinoco System of Horizontal Regional Interdependence (SIRO).

Keywords: Yekuana. Orinoco System of Horizontal Regional Interdependence (SIRO). Indigenous Movements. Venezuela 